\title{
Impact of positive teacher-student interactions on academic resilience in adolescents from the lower socio-economic strata
}

\author{
Mini Narayan \\ ${ }^{1}$ Counsellor, Bunts Sangha's Higher Education Institutions, Mumbai. \\ Corresponding author: Ms. Mini Narayan \\ Email-minianoop@gmail.com
}

\begin{abstract}
Background: As students spend a third of their time in classrooms interacting with teachers, this qualitative study sought to understand the role of teacher-student relationship in the students' subjective construction of academic resilience.

Methods: Individual interviews were conducted with seven at-risk students preparing for the IIT (Indian Institute of Technology) examination through the "Super30" coaching programme, which resembles the traditional "Gurukula" system of learning in that the student (or "Shishya") stays with the teacher during the preparatory period.

Results: Findings showed that Turnaround Teachers engaged in democratic, identity-affirming and virtueprioritizing messages to promote academic excellence in at-risk students. It also brought to light the bidirectional, deeply caring relationships that were at the centre of these interactions. High expectations of teachers as well as appropriate limit setting interventions played a significant role in strengthening socially oriented achievement motivation in students coming from collectivistic cultures.

Conclusion:Findings emphasize the urgent need to strengthen these accessible protective forces by offering necessary educational interventions so that academic success becomes a reality for every child, regardless of external resources.
\end{abstract}

Keywords: Academic resilience, Student-teacher interactions, Socially oriented achievement motivation, Turnaround teachers, Lower socio-economic strata.

(Paper received $-29^{\text {th }}$ December 2017 , Peer review completed $-8^{\text {th }}$ January 2018)

(Accepted $-9^{\text {th }}$ January 2018)

\section{INTRODUCTION}

Resilience: The multidimensional concept of resilience is described as a set of "self-righting tendencies" [1] that helps an individual adapt competently and successfully to severe risks. This "ordinary magic" [2] came under the researchers' lens due to a paradigm shift in psychology - a shift from studying deficits to decoding thriving. For the first time, there were concerted attempts to know what went right with people in spite of the risks they were exposed to. Recent research shows that resilience is not the capacity to be "invulnerable" [3]; rather it is a by-product of synergistic processes acting within and around the individual. When protective forces outweigh risk factors, chances of success are much higher. Recent studies take cognisance of diverse risks including but not limited to parental maltreatment, poverty, maleficent life events, community violence etc.

Academic Resilience: Domain specificity is an interesting aspect that emerges from studies on resilience and refers to the fact that individuals may exhibit domain specific variations in resilience [4]. Academic resilience refers to greater possibilities of academic success despite severe environmental risks. Research 
shows that academic resilience is not a fixed personal attribute available to an "intelligent few". Rather, several "alterable factors" influence academic persistence positive and additively [5]. This crucial finding underscores the possibility of finding ways of nurturing academic resilience in students from the lower socioeconomic strata, who would otherwise be at the risk of academic non-performance.

\section{RATIONALE OF STUDY}

India is a nation beset with widespread poverty. Typically, low socioeconomic status exposes learners to "micro-inequalities" producing adverse effects which are "multiplicative, rather than simply additive" [6]. This could explain the large scale academic deficits of such students in terms of impaired performance, low self-esteem and voluntary abdication of the contexts in which these inequalities are experienced. More than $53 \%$ of Indian students discontinue education before they complete primary school [7]. However, there is no doubt that education is a definitive means of capacity building and increasing opportunities. But, to reap rich demographic dividends, it is essential to identify and strengthen processes that enable atrisk children to persist in their academic pursuits. Research has shown that student-teacher interactions play a vital role in academic success [8-9]. Most studies in this area have, however, ignored the voices and perspectives of academically resilient students and their "felt" experiences of teachers who contributed to mitigation of risks. This study sought to understand the nature and benefits of positive teacher-student interactions from the students' perspective. As motivation systems are culture dependent, the study also aims to explore the significance of facilitative teacher-student interactions within the Indian cultural context. Such an inquiry may reveal aspects that help to bring more Indian students into the ambit of higher education.

The objectives of the current study was to -

- Understand the "felt" experiences of teacher-student interactions from the students' perspective

- Understand the various domains of support students receive from transformative studentteacher relationships

- Explore the significance of teacher-student bonding within the Indian cultural context

\section{METHODOLOGY}

The Ramanujan Institute of Mathematics (RIM) is a coaching facility for IIT aspirants located in Bihar, India. Each year, RIM has a significantly high success rate (almost $98 \%$ ) for their Super30 Program, which offers free residential coaching to 30 high-achieving students from the lower SES, admitted into the program through a nation-wide merit examination. Mandatory requirements for students to be admitted into the program include a) Evidence of high academic achievement (academic scores above $75 \%$ ), b) Evidence of crippling economic condition (type of house, employment status of significant others, education from Government schools), c) Gaining admission through the entrance examination, and d) High motivation for pursuing academic excellence.

\section{Sampling}

A purposive, non-probability sampling method was chosen, and a sample of 6 males and 1 female student comprised the population of the study. 5 students were in the XII standard and 2 students were in XI standard; 2 students belonged to the OBC (Other Backward Caste) and 5 belonged to SC/ST (Scheduled Caste/Scheduled Tribe) categories; parental education of 6 of the students was less than High School level. The teacher Anand Kumar was interviewed in order to better understand the bi-directional interactions between teachers and students.

A life-story method of enquiry [10] was used to facilitate the re-construction of personal narratives. The interviews were in Hindi and were later translated by the researcher. 


\section{RESULTS AND DISCUSSION}

\section{Risks}

Historically, poor contexts and membership in a racial or cultural minority expose students to several risks. In the current study, students experienced the following risks:

Table 1 - Risks Experienced By Students

\begin{tabular}{|c|c|c|c|c|c|c|c|}
\hline Risk Factors & *Shaan & Pulkit & Rahul & Biju & Sabu & Rajah & Kriti \\
\hline \multicolumn{8}{|l|}{ Microsystem } \\
\hline Poverty & $\mathrm{X}$ & $\mathrm{X}$ & $\mathrm{X}$ & $\mathrm{X}$ & $\mathrm{X}$ & $\mathrm{X}$ & $\mathrm{X}$ \\
\hline Difficult Childhood Experiences & $\mathrm{X}$ & $\mathrm{X}$ & $\mathrm{X}$ & $\mathrm{X}$ & $\mathrm{X}$ & $\mathrm{X}$ & $\mathrm{X}$ \\
\hline Parental Unemployment & $\mathrm{X}$ & $\mathrm{X}$ & $\mathrm{X}$ & $\mathrm{X}$ & $\mathrm{X}$ & $\mathrm{X}$ & $\mathrm{X}$ \\
\hline Low Parental Education & $\mathrm{X}$ & $\mathrm{X}$ & $\mathrm{X}$ & $\mathrm{X}$ & $\mathrm{X}$ & $\mathrm{X}$ & $\mathrm{X}$ \\
\hline Unavailability of one/both parents & $\mathrm{X}$ & & & $\mathrm{X}$ & $\mathrm{X}$ & $\mathrm{X}$ & $\mathrm{X}$ \\
\hline High Parental Stress & $\mathrm{X}$ & $\mathrm{X}$ & & & & $\mathrm{X}$ & \\
\hline \multicolumn{8}{|l|}{ Exosystem } \\
\hline Low Income Neighborhood & $\mathrm{X}$ & $\mathrm{X}$ & $\mathrm{X}$ & $\mathrm{X}$ & $\mathrm{X}$ & $\mathrm{X}$ & $\mathrm{X}$ \\
\hline Low Opportunity for Education & $\mathrm{X}$ & $\mathrm{X}$ & $\bar{X}$ & $\mathrm{X}$ & $\mathrm{X}$ & $\mathrm{X}$ & $\mathrm{X}$ \\
\hline \multicolumn{8}{|l|}{ Macrosystem } \\
\hline Minority Status & $\mathrm{X}$ & $\mathrm{X}$ & $\mathrm{X}$ & $\mathrm{X}$ & $\mathrm{X}$ & $\mathrm{X}$ & $\mathrm{X}$ \\
\hline
\end{tabular}

*Names changed to protect confidentiality

The role of teachers in facilitating academic resilience became apparent when each interview spontaneously brought up stories of teachers as unforgettable and invaluable mentors. The "felt" experiences of students showed the teacher's influence in various domains.

Caring Relationships: Biju spoke about how his teacher in the $5^{\text {th }}$ standard, "saw that I was a good student" and helped him with materials (books and stationery) and through timely advice regarding the value of a good education. Her guidance extended to taking him home so he could "see how educated people lived" and making him understand the "need to lead a good life". Pulkit spoke about how his teacher helped him through the personal crisis of his father's death, while Rajah's narrative fondly spoke of the teacher as a "God".Kriti described her teacher as "He [sir] considers me ... as his daughter".

Encouraging positive self-perception: Students spoke of their teacher's positive perception regarding them. Rajah shared that his teachers were happy with and appreciated his hard work. Pulkit spoke about how his teacher "liked that I asked many doubts". Such positive perceptions enabled students to be more engaged in class. Pulkit described the impact of teacher-induced positive self-perception succinctly when he mentioned, "I also began to believe that I have some identity and that if I could reach till here, I can achieve anything".

Positive classroom experiences: Shaan recounted proudly how every child but he was standing after a classroom quiz. Pulkit liked that his teachers called him to solve sums on the blackboard. He went on to say that "when teacher says, we feel OK something significant has happened...so, we start ... [to] work hard". This reinforced existing findings that the emotional climate that pervades the classroom impacts student performances [11].

Effective disciplining: Teachers actively induced hard work and discipline in students. Kirti spoke about how her teacher chided her in class for not completing her work as he knew this impacted her. Her teacher instructed her parents on strategies to stay awake during cold winter nights. Thus, teachers helped students develop the ability to self-regulate as well as defer gratification until an objective was met. Almost every student spoke about how the teacher had discussed back-up plans if they failed to achieve success in the IIT examination, showing that teachers suggested several strategies for anxiety reduction and control.

Belongingness, love respect and acceptance: While showing sensitivity to the deficits that children experienced, teachers extended staunch support to students. Rahul remembered how his teacher had 
acknowledged his academic efforts in class that "you have also started studying!" Pulkit deeply enjoyed the recognition that his success in Math Olympiad garnered. Rajah too spoke about how he had earned a good place in the teacher's heart. Ankit spoke about how his teachers used to "respect and recognize me a lot ... [and] say you think very deeply". In order to motivate students, teachers spontaneously conveyed identityaffirming messages ("Teacher used to say that Ankit will solve the questions"), reality-defining messages ("Studies is the only way in which a person can reach those heights where he cannot really reach otherwise") and future-casting messages ("He used to tell me examples of one [student who] had gone to college for higher education") [12].

High Expectations: Almost every student spoke of how teachers consistently expressed high expectations of their students, which in turn acted as a catalyst for performance and increased student self-efficacy, outcome expectations, direction and perseverance. Pulkit spoke about how his teacher in the $8^{\text {th }}$ standard scolded him for his inability to solve 2-3 questions, and said, "You can do better". Ankit remembered his teacher's comments that "Ankit will solve the questions".

Opportunity for meaningful contribution: Teachers did not limit education to academics alone. They spoke about moral and ethical responsibilities of students as future citizens, underlining previous findings that when adolescents are treated as adults, they respond accordingly [13]. In this study, every student spoke about service to society by providing free coaching to financially weak but deserving students. These students had experienced the benefits of such selfless acts which they wanted to replicate.

Thus, it may be said a key finding of this study is the transformative power of meaningful teacher-student interpersonal relationships as a crucial factor in developing academic resilience in at-risk students and motivating them to pursue further studies with passion.

The Turnaround Teacher: This study portrayed the central role of the 'Turnaround Teacher' [14] in students' decision to pursue higher education. The interview with Mr Anand Kumar revealed that his role was not limited to imparting knowledge but also extended to being a personal coach, friend and role model ("Sir helped ... not only in studies but many other things... what you should do in life, how you should live life" - Kriti). Transformative teachers facilitated the pursuit of education by nurturing a meaningful bond with their students, using respectful and democratic discipline strategies, maintaining and articulating high expectations from students and creating rewarding classroom experiences.

Socially Oriented Achievement Motivation (SOAM): SOAM [15] is seen in collectivistic cultures where significant others a) set achievement goals, b) set the standards of excellence for actions used to pursue goals, c) decide the value of outcomes and d) offer positive or negative reinforcement through praise or blame. The subjective experiences of students showed the importance of social instrumentality in collectivistic cultures, as opposed to self-instrumentality seen in more individualistic cultures. Teachers were seen to have set achievement goals and standards for students, who worked hard to fulfil expectations ("Sir only told me about IIT", "Sir used to make us do so much hard work"). The enormous impact that expectations of significant others like teachers have on academic resilience questions the adequacy of intrinsic motivation rooted in the individualistic paradigm to explain motivational processes across cultures.

\section{IMPLICATIONS}

Findings from this study once again emphasized the need for a paradigmatic shift from individual factors to ecologies that facilitate academic resilience in students from challenging backgrounds. Such a conceptualization focuses on the interactive processes that ensure academic resilience and negates any tendency to unfairly hold the child entirely responsible for not achieving academic success in rigorous streams of education.

The findings also have clear implications for the most important stakeholders primarily involved in academic pursuits - students and teachers. Classrooms were the workplaces for students.Understanding the personal and interpersonal processes that facilitate self-regulated learning in poor students is significant in designing appropriate interventions. When teachers are interested in their students, show concern, offer emotional assistance, and take time to know their students, they satisfy the relatedness needs of students and contribute to greater student self-determination [16]. Teachers provided positive classroom experiences 
thereby increasing students' expectations of success and intrinsic values of the task [17], important predictors of subsequent performance. Hence, encouraging systemic strategies like community-schoolfamily collaborations to create "a culture of achievement" [18] can yield good academic dividends in children with a tendency to drop off the academic grid. Another important finding this study reinforced was that students who have experienced that genuine "connection or encounter between two carers - a carer and a recipient of care" [19] become adults who really remember the teachers "who made the difference" [20].

An associated aspect is the possibility of reviving at least parts of the "Gurukula" system of learning for certain student populations. This model (also followed at Super30) was indigenous to India and was sensitive to the unique local, cultural and economic requirements of students. It thus offered a scheme of imparting personalized and affordable education that matches the pace of the learner. Such a system also provided benefits like peer support, shared resources, effective role models and the experiences of the More Knowledgeable Other. Resilience literature too suggests that "greater the number of positive factors that adolescents reported in their lives, the more positive their academic outcomes" [21-22].

\section{RECOMMENDATIONS FOR FURTHER RESEARCH}

In a country like India, where a huge percentage of learners come from deprived contexts, further research must be carried out into strengthening adaptive systems outside of the individual that ensure higher enrolment and perseverance in academics. Equally important is the need to explore the impediments that operate at the macrosystemic level. For instance, the significant role of the Turnaround Teacher may be a rich area for inquiry as many students living in rural areas struggle with insufficient resources and opportunities. This study showed that teachers play a vital role in overcoming "learned helplessness" in underachieving, at-risk students. Understanding the teaching practices of "turnaround teachers" is significant in view of various literacy and education initiatives by the Government (Eg: The 'Single Teacher School' in the tribal areas of Kerala). Teachers working in such areas literally change the academic trajectories of children, if so equipped. The significant influence of SOAM in the Indian context is another key finding that necessitates that the theories of resilience generated in the West be reconsidered to include unique macro-level and micro-level processes operating within the cultural context.

\section{CONCLUSION}

Academic success is context dependent. In India, where education has traditionally been elitist, gross enrolment rates of students in secondary and higher education are low as a majority of students come from the lower socio-economic strata. For such students to actively participate in academic pursuits, quality education imparted by effective educators is the most important need of the hour. Academic resilience in such student populations alone can propel the nation to higher earnings, productivity and innovations.

\section{REFERENCES}

1. Vaillant GE. The wisdom of the ego. Harvard University Press; 1995.

2. Masten AS. Ordinary magic: Resilience processes in development. Amer Psychol 2001;56(3):227-35.

3. Anthony EJ. The syndrome of the psychologically invulnerable child. Basic Books; 1996.

4. Kaufman J, Cook A, Arny L, Jones B, Pittinsky T. Problems defining resiliency: Illustrations from the study of maltreated children. Dev Psychopathol 1994;6(1):215-29.

5. Narayanan A. Resilience, metacognition, and complexity. J Indian Acad Appl Psychol 2009;63:112-8.

6. Huston AC, McLoyd VC, Coll CG. Children and poverty: Issues in contemporary research. Child Dev 1994;65(2):275-82.

7. Cheney GR, Ruzzi BB, Muralidharan K. A profile of the Indian education system. Prepared for the New Commission on the Skills of the American Workforce. 2005.

8. Cokley K. An investigation of academic self-concept and its relationship to academic achievement in African American college students. J Black Psychol 2000;26(2):148-64.

9. Komarraju M, Musulkin S, Bhattacharya G. Role of student-faculty interactions in developing college students' academic self-concept, motivation, and achievement. J College Stud Dev 2010;51(3):332-42. 
10. Massey S, Cameron A, Ouellette S, Fine M. Qualitative approaches to the study of thriving: What can be learned?. J Soc Issues 1998;54(2):337-55.

11. Verenikina I, Lysaght P, Vialle W. Understanding learning and development. David Barlow Publishing; 2011.

12. Waldron VR, Kloeber D, Goman C, Piemonte N, Danaher J. How parents communicate right and wrong: A study of memorable moral messages recalled by emerging adults. J Fam Commun 2014;14(4):374-97.

13. Rutter M. Resilience concepts and findings: implications for family therapy. J Fam Ther 1999;21(2):119-44.

14. Benard B. Resiliency: What we have learned. WestEd; 2004.

15. Tao VY, Hong YY. When academic achievement is an obligation: Perspectives from social-oriented achievement motivation. J Cross-Cultural Psychol 2014;45(1):110-36.

16. Taylor IM, Ntoumanis N. Teacher motivational strategies and student self-determination in physical education. J Educ Psychol 2007;99(4):747-55.

17. Roeser RW, Eccles JS. Schooling and mental health. In Handbook of developmental psychopathology. (pp. 135-156). Springer US ; 2000.

18. Carter SC. No Excuses: Lessons from 21 High-Performing, High-Poverty Schools. Heritage Foundation, 214 Massachusetts Avenue, NE, Washington, DC 20002; 2000.

19. Noddings N. The Challenge to Care in Schools, 2nd Editon. Teachers College Press; 2015.

20. Werner EE, Smith RS. Overcoming the odds: High risk children from birth to adulthood. Cornell University Press; 1992.

21. Alfaro EC, Umaña-Taylor AJ. Latino adolescents' academic motivation: The role of siblings. Hisp J of Behav Sci 2010;32(4):549-70.

22. Santiago CD, Wadsworth ME, Stump J. Socioeconomic status, neighborhood disadvantage, and povertyrelated stress: Prospective effects on psychological syndromes among diverse low-income families. J Economic Psychol 2011;32(2):218-30.

23. Kuruvilla A, Jacob KS. Poverty, social stress \& mental health. Indian J Med Res 2007;126(4):273-6.

$* * * * * * * * * * * * * * * * * * * * * * * * * *$

Acknowledgements - Ramanujan Institute of Mathematics (context of the research); School of Human Ecology, Tata Institute of Social Sciences (General support for research)

Conflict of Interest - Nil

Funding - Nil 